Review Article

\title{
The Impact of Human Factors on the Safety of Operating Rooms and everyday Surgical Practice
}

\author{
Vasiliki Valla', Angeliki Koukoura $^{2}$, Amy Lewis $^{3}$, Benedicte Dahlerup $^{4}$, Georgios loannis Tsianos $^{5}$, \\ Efstathios Vassiliadis ${ }^{6}$ \\ 1,2,3,4,5,6Evnia, Copenhagen Business Center, Hellerup Strandvejen 60, 2900, Denmark.
} DOI: https://doi.org/10.24321/2394.6539.202002

I $\quad \mathbf{N} \quad \mathbf{F} \quad \mathbf{O}$

\section{Corresponding Author:}

Georgios Ioannis Tsianos, Evnia, Copenhagen Business Center, Hellerup Strandvejen 60, 2900,

Denmark.

E-mail Id:

tgi@oark.dk

Orcid Id:

https://orcid.org/0000-0001-9501-0903

How to cite this article:

Valla V, Koukoura A, Lewis A, Dahlerup B, Tsianos $\mathrm{GI}$, Vassiliadis E. The Impact of Human Factors on the Safety of Operating Rooms and everyday Surgical Practice. J Adv Res Med Sci Tech 2020; 7(1): 8-16.

Date of Submission: 2020-03-12

Date of Acceptance: 2020-05-02
$\begin{array}{lllllllll}\mathbf{A} & \mathbf{B} & \mathbf{S} & \mathbf{T} & \mathbf{R} & \mathbf{A} & \mathbf{C} & \mathbf{T}\end{array}$

\begin{abstract}
Human Factors Engineering (HFE) principles were initially implemented in safety-related procedures in aviation and other high-risk industries to minimize human error-related risks. The introduction of HFE in healthcare aims not to eliminate the 'human factor,' but rather to enable 'engineering' to redesign clinical settings to become resilient to unanticipated events related to operational and/or safety shortcomings. Given the complexity of the Operating Room (OR) and the sociotechnico-cognitive activities that occur during a surgical operation, HFE needs to consider a wide spectrum of Surgical Flow Disruptions (SFD), such as miscommunications, fatigue, workload, physical layout of the site etc. The increase of fully automated/computer-assisted surgical systems into everyday surgical practice highlights the need for specialized technical skills and a subsequent change in mind-set and intraoperative decision-making. The complexity of the modern OR calls out for incorporation of a culture safety also illustrated by the close interaction of Usability Engineering (UE) and Risk Management (RM) throughout the lifecycle of a medical system and by Regulations currently in force. This article discusses the practical parameters of HFE incorporation into surgical practice and aims to highlight how this holistic redefinition of OR settings promotes patient and medical staff safety through mitigation of error-prone processes.
\end{abstract}

Keywords: Human Factor Engineering, Usability Engineering, Risk Management, Surgical Flow Disruption, Human Machine Interface

\begin{abstract}
Abbreviations
AWS: Automated Workflow Systems, BLE: Bluetooth Low Energy, EU-MDR 2017/745: European Medical Device Regulation, HE: Human Error, HFACS: Human Factors Analysis and Classification System, HFE: Human Factors Engineering, HMI: Human-Machine Interface, MD: Medical Device, ME: Medical Error, MI: Machine Interface, OR: Operating Room,
\end{abstract}

PMA: Premarket Approval. PMCF: Post-Market Clinical Follow-up, QA: Quality Assurance, RAS: Robotic Surgical Systems, RM: Risk Management, RTLS: Real-Time Locking (or Tracking) System, SFD: Surgical Flow Disruption, SHEL: Software-Hardware-Environment-Liveware Model, UE: Usability Engineering, UOUP: User Interfaces of Unknown Provenance, WMSD: Musculoskeletal Disorder. 


\section{Background}

Medicine has been largely built on the primum non nocere principle, which reflects a rather human-based perception of accountability. Nevertheless, the evolution of both modern surgery and Operating Rooms (ORs) has rendered the concept that Medical Errors (MEs) are by definition nonintentional Human Errors (HEs) or "failures of planned actions" 1,2 obsolete. Incorporation of complex automated and/or Robotic Surgical Systems (RAS) into the healthcare edifice has resulted in what Hollnagel ${ }^{3}$ defines and later re-discusses as joint "cognitive systems." In order to ensure safety and quality of surgical practice, HEs triggered by teamwork and communication failures (e.g., delays in decision-making, lack of surgical/medical proficiency, poor time management etc.) should be taken into account as well as the technical dexterity and familiarization of healthcare professionals with semi- and fully-automated systems.

The inevitability of $\mathrm{HEs}^{4,5}$ often shifts the liability burden towards Medical Devices (MDs) with the presumption that MD innovation will effortlessly overcome them. But this is far from the reality of surgical practice as systems, per se, are incapable of preventing HEs and worse still, are error-stimulants themselves. The purpose of HFE is to introduce a systems-based approach that coordinates human practices with Machine Interface (MI), providing insight into human-machine interaction for the mitigation of intraoperative adverse events (Figure 1).

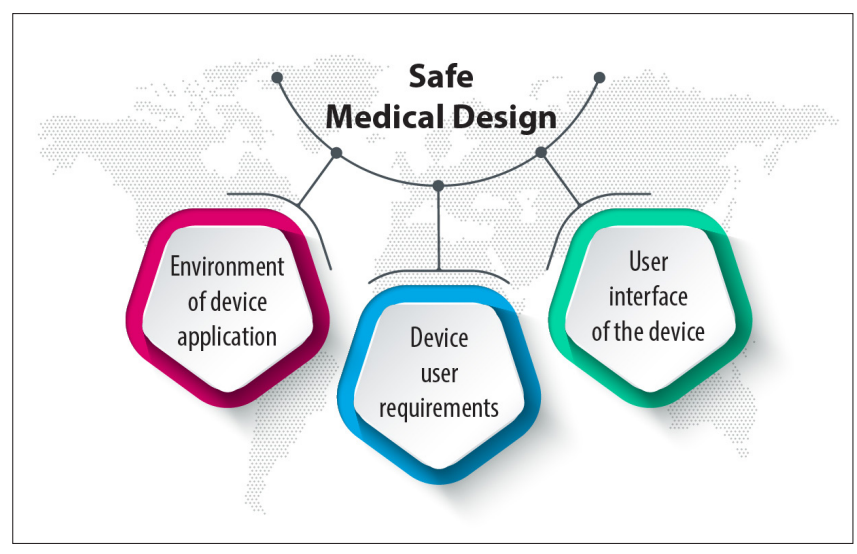

Figure I.Parameters of safe medical device design

We aim to discuss herein practical aspects of distractions associated with surgical practice and to identify HF strategies implemented to mitigate intraoperative risk and error-prone processes and to enhance Human-Machine Interface (HMI).

\section{The Effect of Human Factors on Medical Errors in Operating Rooms}

The exact prevalence, severity and nature of intraoperative patient harm due to potentially preventable HEs is actively debated, ${ }^{6-9}$ and inconsistently reported ${ }^{10}$ due to the focus on individual performance and events rather than organizational processes and mentality patterns. Yet, the available evidence points to a safety gap related to human error. ${ }^{11,12}$

The six-layer hierarchical framework of Rasmussen ${ }^{13}$ and Reason's Swiss cheese model of accident causation ${ }^{1,4}$ have heavily influenced our perception of HEs. The latter considers accidents as active failures (i.e. immediately either discernible or latent), which are the result of deficiencies in the organizational level of a system, and thus are more difficult to identify and more demanding to address. Following Reason's model, many others have emerged trying to delimitate error causation. All of them aim to manage usability of technology, human errors, clinician's performance and system resilience. In terms of unsafe factors, Edward's Software-Hardware-EnvironmentLiveware (SHEL) model, ${ }^{4,11}$ classifies accident causes by individuals, hardware, software, and environment. Based on Reason's framework, Wiegmann and Shappell further extracted systematic HE taxonomy from US Navy aviation accidents and set up the Human Factors Analysis and Classification System (HFACS). ${ }^{14}$ Most, if not all, of these models were initially used in high-risk industries such as aviation or nuclear and were adopted by surgical practice when automation levels began to challenge the traditional operational modes and communication of interdisciplinary staff.

There are numerous studies associating HFs to surgical practice mainly focusing on communication deficiencies, OR design, environmental factors, and technical surgical errors. ${ }^{11,12,14-17}$

Communication deficiencies can be an exhausting burden for surgical settings as they are running through all stages of surgical operation. Wiegmann et al. ${ }^{18}$ used direct observation to study and characterize disruptions in the cardiac OR and found that miscommunication occurred an average of nine times per operation, while disruptions primarily consisted of teamwork and communication failures, which were also the strongest predictor of surgical errors. Lingard et al. ${ }^{19}$ completed an observational study to further deconstruct communication failures in the $\mathrm{OR}$, and ultimately observed communication failures caused by poor timing, inaccurate or incomplete information, failure to include key team members, or failure to resolve issues in $31 \%$ of OR communications. ElBardissi et al. ${ }^{20}$ found a strong correlation between the occurrence of technical errors and teamwork failure in 31 cardinal surgical sites. The above suggest that interventions to mitigate communication deficiencies could also improve intraoperative communication and patient safety. Frasier et al. ${ }^{21}$ performed a purposive sampling on 10 operations and identified lower communication rates among crossdisciplinary duos, which was associated with a higher 
incidence of ineffective communication events. Wakeman et al. ${ }^{22}$ focus on pediatric surgery and explain that unless team dynamics are well-established, unconscious psychological forces are constantly jeopardizing the performance of teamwork as well as their situational awareness.

Beyond the characteristics and behaviors of the individuals at the center of the system, a number of systems-based factors influencing surgical safety have been explored, such as the high level of environmental interference in the $\mathrm{OR}^{23}$ and the significant negative impact of poor $\mathrm{OR}$ layout and design on surgical workflow. Antoniadis et al. ${ }^{23}$ studied 65 surgical cases in two German clinics and identified at least 11 intraoperative distractions, which were observed 9.82 times per hour on average. Jung et al. ${ }^{24}$ conducted a prospective cohort study in 265 consecutive patients undergoing laparoscopy and reported that the attending surgeon was distracted by both cognitive and auditory sources in about $45 \%$ of cases. Environmental factors within the OR such as noises, ${ }^{12}$ improper lighting or temperature, congestion due to excessive wiring or location of equipment and displays ${ }^{16,25}$ have been associated with OR hazards. Raghavendra et al. ${ }^{26}$ emphasize that apart from intraoperative impairments that may have a direct negative impact on the clinical outcome, ergonomic and layout deficiencies are also linked to potential pollution events, increase of workload and fatigue as well as physical problems including back and neck issues. Catanzarite et al. ${ }^{15}$ support the latter remark and have shown that musculoskeletal disorders (WMSDs) are highly prevalent among surgeons of all specialties but particularly among laparoscopy and RA surgeons with an impact on work absenteeism, decreased productivity and work-related injuries. The authors also suggest design modifications such as standing supports, height details for monitors and tables, working angles etc. to prevent intraoperative injuries among the surgical team.

\section{Surgical Flow Disruptions and HFE in Operating Rooms}

Identification and quantification of systemic intraoperative errors can be quite a challenge especially on retrospective level given the inherent hindsight bias. ${ }^{12,16,27}$ This has led researchers to look for indirect predictors of irreversible or fatal events, such as flow disruptions. Through the observation of 31 cardiac surgery operations, Wiegmann et al. ${ }^{18}$ have proposed the distinction of surgical errors and Surgical Flow Disruptions (SFDs) defining the latter as "deviations from the natural progression of an operation that potentially compromise the safety of the operation." ElBardissi et al. ${ }^{20}$ have categorized SFDs according to their origins, i.e. issues with teamwork/ communication, extraneous interruptions, equipment-related problems, resource-based issues and supervisory/ training-related issues ${ }^{18}$. These factors, independently or in combination, serve as indicators of surgical performance as they can predict the likelihood of an undesired event, which may bear unwanted consequences to the patient, the surgical staff or the OR operation.

Several observational tools, methodologies and analytical approaches have since been developed to identify and address SFDs. ${ }^{14,16,28-30}$ The interventions most often proposed in the literature and used in surgical practice include use of checklists, ${ }^{12,28,31}$ preoperative briefing, ${ }^{12}$ team workbased training courses, ${ }^{12,27}$ usability testing to enhance surgical safety, ${ }^{15,23,26,32,33}$ standardization of processes and development of a culture safety. ${ }^{16,34}$ Although most of the above may be considered as 'common sense, ${ }^{33}$ the effectiveness of an HFE program designed to address OR resiliency cannot be taken for granted. All interventions depend on the timely and accurate reporting of safety events and the willingness of surgical staff to adapt their working mentality towards reporting, flexibility and relearning. For example, checklists will not be effective unless routinely used by the entire team. More than that, no matter how many HEs a usability test will identify, unless training, development of skills and familiarization with $\mathrm{MI}$ is cultivated, the complexity of patient physiology will always be an obstacle between the surgeon and the HFE interventions. A non-exhaustive list of currently used HFE applications includes:

- $\quad$ Real-Time Locking (or Tracking) Systems (RTLS) to identify and locate tagged equipment, personnel or patients ${ }^{35-37}$

- Automated Workflow Systems (AWS) to enhance OR communication $^{38-40}$

- New web-based Training Platforms for Medical Device operation ${ }^{41,42}$

- Decision Support Systems for OR scheduling ${ }^{43,44}$

Altogether, evidence indicates that hospital staff (medical, nursing and technical) is responding positively to the increasing trend of HMI automation but usability issues (e.g. technical limitations, solution functions, operational support, user-friendly working environment) are determinants of its potential universal acceptance (Figure 2).

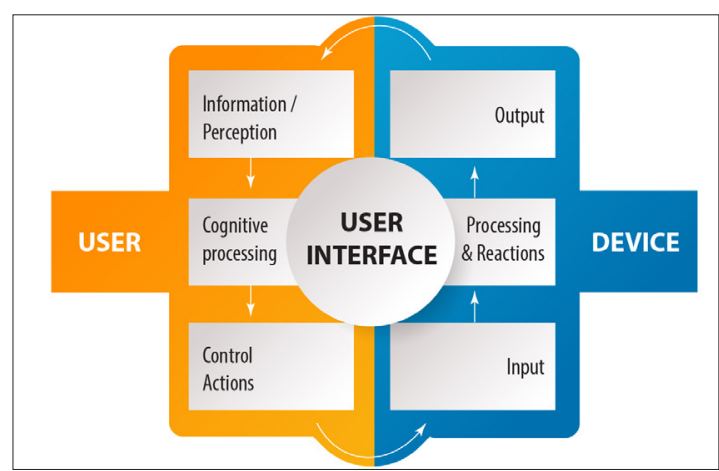

Figure 2.Overview of the human-machine interface (HMI) 
For example, Yoo et al., ${ }^{37}$ have recently implemented a RTLS based on Bluetooth Low Energy (BLE)/WiFi sensor beacons in a tertiary care hospital. After 3 months of use, 117 nurses were moderately satisfied with the intervention and willing to re-use it. Interestingly, younger age and higher expertise (ER nurses) were positively associated with end-user satisfaction. Fisher et al., ${ }^{35}$ who observed 23 US hospitals that had implemented RTLS for 3 years, highlight the need for usability optimization but explain that a simultaneous deployment of changes in the organizational culture of healthcare settings is also required to overcome operational drawbacks. Gholamhosseini et al. ${ }^{36}$ provide similar feedback and propose more elaborate use of cloud computing and interrelated computing devices to overcome current limitations.

AWSs constitute an advanced checklist system sufficiently proven to contribute to stuff communication, patient safety and timeout efficiency. Their user-friendly profile and consistency have improved the traditional standard checklist measures and have significantly increased medical staff compliance with respect to systematic use. Vankipuram et al. ${ }^{40}$ have proposed to use a system of motion and location recordings via radio identification tags and observations to enhance clinical workflow analysis even further by continuous updates with real-world data.

Web-based training platforms enable familiarization with these systems, while being a pillar for the improvement of staff performance and development of Risk Management (RM) and Quality Assurance (QA) systems. ${ }^{41,42}$

\section{Hands on Innovation: Pioneering Concepts in Medical Device Ergonomics/ HMI Interface/ Application Risk}

Introduction of DAVINCI ${ }^{\circledR}$, the first RAS System, in early 2000 , has been a milestone of the field and resulted in the expansion of RAS indications $\mathrm{s}^{45,46}$ and introduction of several similar systems into the market, ${ }^{47}$ which brought up debates on the benefit-risk profile of the approach. Benefits for the patient include significantly reduced hospitalization time, minimal scarring and fewer complications, while surgeons benefit from ergonomics, magnified views, improved tissue manipulation and instrument stability. ${ }^{47-50}$ Conversely, downsides include the level of surgical dexterity and required device-specific experience, increased operational and purchasing costs, lack of haptic feedback, systems' size, inability to promptly switch instruments during a procedure ${ }^{47,51-53}$ and relatively high rates of robot-associated complications. ${ }^{54}$

Taking the above into consideration, Schuler et al. ${ }^{55}$ ask "who is the boss in RAS" and after reviewing a considerable number of related clinical trials and profiles of RAS, propose the use of HFE to avoid the downsides.
Introducing new technologies into the OR fundamentally changes the requirements for teamwork and intraoperative communication, coordination and individual skills. Therefore, extensive training in simulation environments (for a more efficient management of complications), intraoperative real-time feedback to the surgeon (via safe surgery pathways), anatomical borders, and improved documentation mechanisms (e.g. checklists to facilitate the improvement of complication rates) are essential HFErelated interventions.

Souders et al. ${ }^{56}$ have observed 24 robotic abdominal sacrocolpopexy procedures for SFDs and deviations from optimal course of care and have found that they occurred every six minutes. Increased robotic surgery experience was associated with a decreased overall FD rate and SFD rates correlated negatively with surgery duration.

Dru et al. ${ }^{57}$ studied 34 robotic-assisted radical prostatectomy and bilateral pelvic lymph node dissections over a 20 week period for SFDs and showed that disruptions of communication, coordination and equipment, were the commonest and all inversely proportional to the surgeon's robotic experience.

Catchpole et al. ${ }^{16}$ provide extensive insight into RAS and highlight the importance of user-centered design with respect to workflow disruptions and communication failures. The authors performed a direct observation of SFDs in 89 RAS cases. They found a mean of 9.62 FDs per hour, predominantly caused by coordination, communication, equipment, and training deficiencies, varying with surgeon experience, training and surgical specialty. It was also shown that almost $60 \%$ of communication FDs are attributed to the need of repetitions since the surgeon does not stand next to the operating table.

With respect to environmental/organizational aspects, Ahmad et al. ${ }^{58}$ studied the impact of OR layout to staff movements. The team identified movements between zones related to staff, movement time and reason for movement and showed that the robotic system was significantly interfering with them as many movements occurred in a relatively confined area, partially due to RAS size and configuration.

Traditional OR grapples with the severe bottlenecks discussed above on a daily basis. The IOR aims to empower the surgical team by reducing intraoperative hazards and dysfunctionalities ${ }^{59}$ (e.g. live "broadcasting" of patient information, audio-visual systems of communication, surgical and room lights, building automation, surgical equipment) and enhancing manipulation of the system from a central command console. Kurmanm et al. ${ }^{2}$ suggest that transition towards IORs addresses and generates improved ergonomics, communication protocols and turnover times. 
Bharathan et al. ${ }^{60}$ claim that IORs may overcome a number of workflow disruptions such as fatigue and disrupting communication since all unnecessary communications may be excluded according to the logic of a "sterile cockpit."

In an effort to determine the parameters of an optimal IOR dedicated to neurosurgery, Bernardo ${ }^{61}$ explained that a flexible, cable-free, wireless, versatile OR can serve as a simplified control interface that adds extra senses to the surgical team, enriching their 'reality' with additional information. The authors highlight that IORs are a costeffective solution for healthcare systems because, through the implementation of HFE, they minimize the HE potential by bridging the gap between surgical planning and accurate execution.

Nakamura et al. ${ }^{62}$ reported on an endoscopic endonasal approach performed in a Smart Cyber Operating Theater (SCOT) to treat a pituitary adenoma and argue in favor of OR integration as it enhances decision-making by providing information in real time and optimizes intraoperative data display, thus facilitating the actual surgical process.

Klein et al. ${ }^{63}$ compared a traditional OR with a commercially available IOR aiming to investigate the impact of optimized ergonomics and technical aids of the latter to psychological and physiological stress of 10 experienced laparoscopic surgeons and showed that transfer of surgeons into an IOR resulted in a significant decrease of complaints during the surgical procedure.

Overall, the development of surgery and automationrelated skills, training and modification of our perception for teamwork and situational awareness become conditio sine qua non for surgical practice. Integrated surgical technologies pose challenges beyond the clinical skills, whilst, workload, if not responsibility itself, is often shifted to technical team-members. Therefore, although, workflow disruptions occur at similar rates to traditional surgery, IORs counterbalance their shortcomings with access to state-of-the-art HFE applications. ${ }^{64,65}$

The regulatory framework for IORs remains vague, mainly due to connectivity/concurrent functioning of differently classified MDs (e.g. patient monitors and anesthesiainducing devices). Nevertheless, informatics-driven platforms able to provide real-time, interactive guidelines to a surgical team are about to become an established reality, directly linked to HFE and expected to bring about a paradigm shift in surgical practice.

\section{Usability Engineering and Risk Management from a regulatory Perspective}

To keep up with the above-described current and future demands, UE must be considered throughout the life-cycle of an MD, i.e., from concept phase to final validation and then during the post-launch phase. The latest version of usability standard IEC 62366-1:2015 ${ }^{66}$ focuses on safety and potential use errors and significantly strengthens links to RM (i.e. ISO $14971^{67}$ ), which supports UE vis-à-vis decisions on the performance of summative tests (e.g. identification of UI with potential safety gaps). ISO 14971 implements the initial 'risk assessment' characterized by HF/UE preliminary analyses, identifies and sets up 'implementing risk controls', corresponding to UI and calls $\mathrm{HF} / \mathrm{UE}$ to implement the findings in an effort to mitigate risk as reasonably as possible. Similarly, IEC $80001-1,{ }^{68}$ specific to IT networks incorporating MDs, provides a background check for modular MD integration in clinical IT networks and defines the elements of risk analysis with respect to HMI.

The new European Medical Device Regulation (EU-MDR $2017 / 745)^{69}$ has strengthened the correlation of usability with RM even further, since any change in MD design shall now be evaluated for its potential impact to the MD benefit/ risk ratio. This risk-oriented process integrates UE into the dynamic RM program, therefore, intensifies attention to use errors and upgrades HFs in clinical settings. Overall, Manufacturers ${ }^{70}$ are required to eliminate or reduce risks related to error use, to consider use by lay persons and to provide feedback from Post-Market Clinical Followups (PMCF). More than that, EU-MDR 2017/745 requires compliance with IEC 62366 with respect to user interfaces of unknown provenance (UOUP), i.e. Manufacturers are expected to justify any potential design change that could be affecting the $\mathrm{UI}$ (e.g. text reconfiguration in a label could trigger a non-UOUP status and therefore the obligation to implement the whole process).

Regulation for UE is also closely related to quality management processes. The latest revision of ISO $13485^{71}$ underlines both RM and UE and introduces usability requirements (e.g. user training to ensure safe use of $\mathrm{MD}$ ) to the design and development section in 2 clauses $^{72}$.

FDA has been addressing HFE for decades and its most recent guidance on HFs highlights the importance of promoting patient safety by implementing HFE during the design and manufacturing of MDs. FDA's 21 CFR 820.30 (Design Controls) $^{73}$ lays out the regulatory basis when applying for a 510 (k) or Pre-Market Approval (PMA) and pinpoints that design input should include needs of the user and patient while performance criteria and safe use should be part of design verification and validation.

Van der Peijl et al. ${ }^{74}$ have provided a practical example of how IEC 62366 is implemented in the development of ventilator systems. They demonstrated it is possible to introduce a concrete UE process into a regular, linear product development process and the respective identification and control of use-related risks through the design for riskcontrol process. 


\section{Conclusion}

The extensive scope of the topic as well as the methodological complexity of HFs research has not allowed for a comprehensive meta-analysis of available data. Instead, we have chosen to present a qualitative review of real world evidence, which provide an insight on many shortcomings of patient safety and working conditions of surgical teams associated with the absence of HFE in ORs and insufficient UE processes in the design of medical systems. Literature evidence explains why the modern OR is a socio-technical milieu with cognitive traits and increased situational awareness needs. Therefore, implementation of HFE principles, namely, a shift towards efficient reporting, dynamic learning and familiarization with humans and automated systems, is a holistic re-definition and upgrade of clinical outcomes, productivity, safety and HMI interactions aiming to establish a sustainable, safe environment for both patients and medical staff.

\section{Acknowledgement: Not applicable \\ Sources of Funding: None Conflict of Interest}

Vasiliki Valla, Angeliki Koukoura and Amy Lewis are employed by Evnia Group as Medical Writers. Efstathios Vassiliadis is the CEO and owner of Evnia Group. No other conflicting interests exist.

\section{References}

1. Reason J. Human error: models and management. $B M J$ 2000; 320(7237): 768-770.

2. Kurmann A, Tschan F, Semmer NK, Seelandt J, Candinas D, Beldi G. Human factors in the operating room - The surgeon's view. Trends in Anaesthesia and Critical Care. 2012; 2(5): 224-227.

3. Hollnagel E. Human factors/ ergonomics as a systems discipline? "The human use of human beings" revisited. Appl Ergon 2014; 45(1): 40-44.

4. D’Addessi A, Bongiovanni L Fau - Volpe A, Volpe A Fau - Pinto F, Pinto F Fau - Bassi P, Bassi P. Human factors in surgery: from Three Mile Island to the operating room. Urol Int 2009; 83(3): 249-257.

5. Kohn LT. To err is human: building a safer health system. MS D, editor. Washington DC: National Academies Press; 2000.

6. Alsubaie H, Goldenberg M, Grantcharov T. Quantifying recall bias in surgical safety: a need for a modern approach to morbidity and mortality reviews. Can J Surg 2019; 62(1): 39-43.

7. Bosma E, Veen EJ, Roukema JA. Incidence, nature and impact of error in surgery. BJS (British Journal of Surgery) 2011; 98(11): 1654-1659.

8. Kim FJ, da Silva RD, Gustafson D, Nogueira L, Harlin T,
Paul DL. Current issues in patient safety in surgery: a review. Patient Safety in Surgery 2015; 9(1): 26.

9. Panagioti M, Khan K, Keers RN, Abuzour A, Phipps $D$, Kontopantelis E et al. Prevalence, severity, and nature of preventable patient harm across medical care settings: systematic review and meta-analysis. BMJ 2019; 366: 14185.

10. White AD, Skelton M, Mushtaq F, Pike TW, MonWilliams $\mathrm{M}$, Lodge JP et al. Inconsistent reporting of minimally invasive surgery errors. Ann R Coll Surg Engl 2015; 97(8): 608-612.

11. Carayon P, Xie A Fau - Kianfar S, Kianfar S. Human factors and ergonomics as a patient safety practice. BMJ 2014; 23(3): 196-205.

12. Shouhed D Fau - Gewertz B, Gewertz B Fau - Wiegmann D, Wiegmann D Fau - Catchpole K, Catchpole K. Integrating human factors research and surgery: a review. Arch Surg 2012; 147(12): 1141-1146.

13. Rasmussen J PA, Goodstein LP. Cognitive Systems Engineering. New York: Wiley; 1994.

14. Cohen T. A Human Factors Approach for Identifying Latent Failures in Healthcare Settings. Daytona Beach, Florida: Embry-Riddle Aeronautical University; 2017.

15. Catanzarite T Fau - Tan-Kim J, Tan-Kim J Fau - Whitcomb EL, Whitcomb El Fau - Menefee S, Menefee S. Ergonomics in Surgery: A Review. Female Pelvic Med Reconstr Surg 2018; 24(1): 1-12.

16. Catchpole K, Bisantz A, Hallbeck MS, Weigl M, Randell $\mathrm{R}$, Kossack $\mathrm{M}$ et al. Human factors in robotic assisted surgery: Lessons from studies 'in the Wild'. Appl Ergon 2019; 78: 270-276.

17. Tabibzadeh M, Jahangiri $G$, editors. A Proactive Risk Assessment Framework to Enhance Patient Safety in Operating Rooms 2018: Springer International Publishing.

18. Wiegmann DA, ElBardissi Aw Fau - Dearani JA, Dearani Ja Fau - Daly RC, Daly Rc Fau - Sundt TM, $3^{\text {rd }}$, Sundt TM, 3rd. Disruptions in surgical flow and their relationship to surgical errors: an exploratory investigation. Surgery 2007; 142(5): 658-665.

19. Lingard LES, Whyte S, Regehr G, Baker GR, Reznick R, Bohnen J, Orser B, Doran D, Grober E. Communication failures in the operating room: an observational classification of recurrent types and effects. Qual Saf Health Care 2004; 13(5): 330-334.

20. ElBardissi AW, Wiegmann Da Fau - Henrickson S, Henrickson S Fau - Wadhera R, Wadhera R Fau - Sundt $T M, 3 r d$, Sundt TM, $3^{\text {rd }}$. Identifying methods to improve heart surgery: an operative approach and strategy for implementation on an organizational level. Eur J Cardiothorac Surg 2008; 34(5): 1027-1033.

21. Frasier LL, Pavuluri Quamme SR, Ma Y, Wiegmann D, Leverson G, DuGoff EH et al. Familiarity and 
Communication in the Operating Room. Journal of Surgical Research 2019; 235(395-403).

22. Wakeman $D$, Langham MR, Jr. Creating a safer operating room: Groups, team dynamics and crew resource management principles. Semin Pediatr Surg 2018; 27(2): 107-113.

23. Antoniadis S, Passauer-Baierl S, Baschnegger $\mathrm{H}$, Weig M. Identification and interference of intraoperative distractions and interruptions in operating rooms. $J$ Surg Res 2014; 188(1): 21-29.

24. Jung JJ, Elfassy J, Grantcharov T. Factors associated with surgeon's perception of distraction in the operating room. doi: 10.1007/s00464-019-07088-z. Surgical Endocscopy 2019.

25. Vaisbuc Y, Moore JM, Jackler RK, Vaughan J, editors. Operating Room Ergonomics: A Practical Approach for Reducing Operating Room Ergonomic Hazards: Springer International Publishing. 2018.

26. Raghavendra Rao RS. Ergonomical aspects of anaesthetic practice. Indian J Anaesth 2016; 60(5): 306-311.

27. de Korne DF, Loh HP, Yin S. Human Factors and Operating Room Design Challenges. In: Sanchez JA, Barach P, Johnson JK, Jacobs JP, editors. Surgical Patient Care: Improving Safety, Quality and Value. Cham: Springer International Publishing 2017; 373-395.

28. Bas E. An integrated OSH risk management approach to surgical flow disruptions in operating rooms. Safety Science 2018; 109: 281-293.

29. Palmer GAJ, Swinton G, Allison D, Greenstein J, Shappell S, Juang K, Reeves ST. Realizing improved patient care through human-centered operating room design: a human factors methodology for observing flow disruptions in the cardiothoracic operating room. Anesthesiology 2013; 119(5): 1066-1077.

30. Sevdalis N FD, Undre S, Darzi A, Vincent C. Annoyances, disruptions, and interruptions in surgery: the Disruptions in Surgery Index (DiSI). World J Surg 2008; 32(8): 1643-1650.

31. Oppikofer C, Schwappach D. The Role of Checklists and Human Factors for Improved Patient Safety in Plastic Surgery. Plast Reconstr Surg 2 2017; 140(6): 812e-7e.

32. Hu YY AA, Roth EM, Peyre SE, Corso KA, Swanson RS, Osteen RT, Schmitt P, Bader AM, Zinner MJ, Greenberg CC. Protecting patients from an unsafe system: the etiology and recovery of intraoperative deviations in care. Ann Surg 2012; 256(2): 203-210.

33. Marshall SD, Touzell A. Human factors and the safety of surgical and anaesthetic care. Anaesthesia 2020; 75(S1): e34-e8.

34. Mueller BU, Neuspiel DR, Fisher ERS. Principles of Pediatric Patient Safety: Reducing Harm Due to Medical Care. Pediatrics 2019; 143(2): e20183649.
35. Fisher JA, Monahan T. Evaluation of real-time location systems in their hospital contexts. Int J Med Inform 2012; 81(10): 795-712.

36. Gholamhosseini L, Sadoughi F, Safaei A. Hospital Real-Time Location System (A Practical Approach in Healthcare): A Narrative Review Article. Iran J Public Health 2019; 48(4): 593-602.

37. Yoo S, Kim S, Kim E, Jung E, Lee K-H, Hwang H. Real-time location system-based asset tracking in the healthcare field: lessons learned from a feasibility study. BMC Med Inform Decis Mak 2018; 18(1): 80.

38. Doebbeling BN BM, Wiebke EA, Miller S, Baxter L, Miller D, Alvarez J, Pekny J. Optimizing perioperative decision making: improved information for clinical workflow planning. AMIA Annu Symp Proc 2012; 2012(154-163).

39. Nissan J, Campos V, Delgado H, Matadial C, Spector S. The Automated Operating Room: A Team Approach to Patient Safety and Communication. JAMA Surgery 2014; 149(11): 1209-1210.

40. Vankipuram M, Kahol K, Cohen T, Patel VL. Toward automated workflow analysis and visualization in clinical environments. Journal of Biomedical Informatics 2011; 44(3): 432-440.

41. Chen M-F, Tsai C-L, Chen Y-H, Huang Y-W, Wu C-N, Chou $C$, et al. Web-Based Experience Sharing Platform on Medical Device Incidents for Clinical Engineers in Hospitals. Journal of Medical and Biological Engineering 2018; 38(5): 835-844.

42. Flowers MG, Aggarwal R. Second Life ${ }^{\mathrm{TM}}$ : a novel simulation platform for the training of surgical residents. Expert Review of Medical Devices 2014; 11(2): 101-103.

43. Vali Siar MM, Gholami S, Ramezanian R. Multi-period and multi-resource operating room scheduling and rescheduling using a rolling horizon approach: a case study. Journal of Industrial and Systems Engineering 2017; 10(special issue on healthcare): 97-115.

44. van Essen JT, Hurink JL, Hartholt W, van den Akker BJ. Decision support system for the operating room rescheduling problem. Health Care Management Science 2012; 15(4): 355-372.

45. Carpenter BT, Sundaram CP. Training the next generation of surgeons in robotic surgery. Robot Surg 2017; 4: 39-44.

46. Dirhold BM, Citak M, Al-Khateeb H, Haasper C, Kendoff $D$, Krettek $C$ et al. Current state of computer-assisted trauma surgery. Curr Rev Musculoskelet Med 2012; 5(3): 184-191.

47. Peters BS, Armijo PR, Krause C, Choudhury SA, Oleynikov $D$. Review of emerging surgical robotic technology. Surgical Endoscopy 2018; 32(4): 1636-1655.

48. Ploussard G. Robotic surgery in urology: facts and 
reality. What are the real advantages of robotic approaches for prostate cancer patients? Curr Opin Urol 2018; 28(2): 153-158.

49. Rodriguez-Sanjuan JC, Gomez-Ruiz M, Trugeda-Carrera S, Manuel-Palazuelos C, Lopez-Useros A, Gomez-Fleitas M. Laparoscopic and robot-assisted laparoscopic digestive surgery: Present and future directions. World J Gastroenterol 2016; 22(6): 1975-2004.

50. Tsui C, Klein R, Garabrant M. Minimally invasive surgery: national trends in adoption and future directions for hospital strategy. Surg Endosc 2013; 27(7): 2253-2257.

51. Nik-Ahd F, Souders CP, Houman J, Zhao H, Chughtai B, Anger JT. Robotic Urologic Surgery: Trends in Food and Drug Administration-Reported Adverse Events Over the Last Decade. J Endourol 2019; 33(8): 649-654.

52. Oleynikov D. Robotic surgery. Surg Clin North Am. 2008; 88(5): 1121-1130.

53. Simorov A, Otte RS, Kopietz CM, Oleynikov D. Review of surgical robotics user interface: what is the best way to control robotic surgery? Surg Endosc 2012; 26(8): 2117-2125.

54. Alemzadeh H, Raman J, Leveson N, Kalbarczyk Z, Iyer RK. Adverse Events in Robotic Surgery: A Retrospective Study of 14 Years of FDA Data. PLoS One 2016; 11(4): e0151470.

55. Schuler PJ. Robotic Surgery - Who is The Boss? Laryngorhinootologie 2018; 97(S 01): S231-S78.

56. Souders CP, Catchpole K, Hannemann A, Lyon R, Eilber $\mathrm{KS}$, Bresee $\mathrm{C}$ et al. Flow disruptions in robotic-assisted abdominal sacrocolpopexy: does robotic surgery introduce unforeseen challenges for gynecologic surgeons? Int Urogynecol J 2019; 30(12): 2177-2182.

57. Dru CJ, Anger JT, Souders CP, Bresee C, Weigl M, Hallett E et al. Surgical flow disruptions during robotic-assisted radical prostatectomy. Can J Urol 2017; 24(3): 88148821.

58. Ahmad N, Hussein AA, Cavuoto L, Sharif M, Allers JC, Hinata $\mathrm{N}$ et al. Ambulatory movements, team dynamics and interactions during robot-assisted surgery. BJU Int 2016; 118(1): 132-139.

59. Garbey M, Joerger G, Huang A, Salmon R, Kim J, Sherman $\mathrm{V}$ et al. An intelligent hospital operating room to improve patient health care. Journal of Computational Surgery 2015; 2(1): 3.

60. Bharathan R, Aggarwa IR, Darzi A. Operating room of the future. Best Pract Res Clin Obstet Gynaecol 2013; 27(3): 311-322.

61. Bernardo A. The Changing Face of Technologically Integrated Neurosurgery: Today's High-Tech Operating Room. World Neurosurgery 2017; 106: 1001-1014.

62. Nakamura T, Ogiwara T, Goto T, Fujii Y, Miyaoka Y, Hanaoka $Y$ et al. Clinical Experience of Endoscopic Endonasal Approach in the Innovative, Newly
Developed Operating Room "Smart Cyber Operating Theater (SCOT)". World Neurosurg 2019; 9: 293-296.

63. Klein M AL, Alamili M, Gögenur I, Rosenberg J. Psychological and physical stress in surgeons operating in a standard or modern operating room. Surg Laparosc Endosc Percutan Tech 2 2010; 20(4): 237-242.

64. Catchpole KR, Hallett E, Curtis S, Mirchi T, Souders CP, Anger JT. Diagnosing barriers to safety and efficiency in robotic surgery. Ergonomics 2018; 61(1): 26-39.

65. Kopelman Y Fau - Lanzafame RJ, Lanzafame Rj Fau - Kopelman D, Kopelman D. Trends in evolving technologies in the operating room of the future. JSLS 2013; 17(2): 171-173.

66. ISO. International Organization for Standardization. Medical devices - Part 1: Application of usability engineering to medical devices (IEC 62366-1:2015). 2015.

67. ISO. International Organization for Standardization. 14971:2019. Medical devices - Application of risk management to medical devices. 2019.

68. ISO. International Organization for Standardization. Medical. IEC 80001-1:2010. Application of risk management for IT-networks incorporating medical devices - Part 1: Roles, responsibilities and activities. 2010.

69. EU-MDR(2017/745). Regulation (EU) 2017/745 of the European Parliament and of the Council of 5 April 2017 on medical devices, amending Directive 2001/83/EC, Regulation (EC) No 178/2002 and Regulation (EC) No 1223/2009 and repealing Council Directives 90/385/ EEC and 93/42/EEC. April 5, 2017.

70. ANNEX-I. EU-MDR(2017/745). ANNEX I: General Safety and Performance Requirements: SPR1: [...] Performance and safety: the medical device shall be 'designed and manufactured in such a way' that safety of patients and users shall not be compromised under the normal conditions of use. The design and construction should conform to safety principles, taking into account the 'generally acknowledged state of the art [...]; SPR5: [...] In eliminating or reducing risks related to use error, the Manufacturer shall:(a) reduce as far as possible the risks related to the ergonomic features of the device and the environment in which the device is intended to be used (design for patient safety) [...]; SPR 6: [...] The characteristics and performance of a device shall not be adversely affected to such a degree that the health or safety of the patient or the user and, where applicable, of other persons are compromised during the lifetime of the device, as indicated by the manufacturer, when the device is subjected to the stresses which can occur during normal conditions of use and has been properly maintained in accordance with the manufacturer's instructions.[...]; SPR 14: [...] Devices shall be designed 
and manufactured in such a way as to remove or reduce as far as possible: [...] (a) the risk of injury, in connection with their physical features, including the volume/ pressure ratio, dimensional and where appropriate ergonomic features; [...] Any measurement, monitoring or display scale shall be designed and manufactured in line with ergonomic principles, taking account of the intended purpose, users and the environmental conditions in which the devices are intended to be used [...]; SPR 22: [...] Devices for use by lay persons shall be designed and manufactured in such a way as to: 1.ensure that the device can be used safely and accurately by the intended user at all stages of the procedure, if necessary after appropriate training and/or information, 2.reduce, as far as possible and appropriate, the risk from unintended cuts and pricks such as needle stick injuries, and 3.reduce as far as possible the risk of error by the intended user in the handling of the device and, if applicable, in the interpretation of the results. [...].

71. ISO. International Organization for Standardization. Medical devices - Quality management systems Requirements for regulatory purposes (ISO 13485: 2016). 2016.

72. ISO(13485:2016). Clause 7.3.3 a: [...] Usability and safety requirements according to the intended use shall be determined and recorded as an input for design and development [...]; Clause 7.3.9: [...] Significant of the change to usability for medical devices and its intended use shall be determined as part of control of design and development changes [...]. 2016.

73. 21CFR820.30. Part 820 -Quality System Regulation. Subpart C- Design Controls. Sec. 820.30 Design controls. 2019.

74. van der Peijl J, Klein J, Grass C, Freudenthal A. Design for risk control: the role of usability engineering in the management of use-related risks. J Biomed Inform 2012; 45(4): 795-812. 